\title{
CHANGES DISSIPATION ENERGY OF CORTICAL BONE DEPENDING ON THE STORAGE METHOD
}

\author{
A. Mazurkiewicz ${ }^{*}$, A. Andrzejewska ${ }^{* *}$, T. Małek $^{* * *}$
}

\begin{abstract}
The study shows changes in dissipation and elastic energy in the porcine cortical bone depending on the storage method. The study included 30 samples of bone. All samples immediately after collection, were subjected to a compression test. Next, the samples were divided into three groups. The groups $(n=10)$ where stored in a $10 \%$ formalin solution, frozen at $-20^{\circ} \mathrm{C}$ and in a $96 \%$ alcohol solution at room temperature for 30 days. After 30 days samples were subjected to the same test. The test results were used to calculate the dissipation and elastic energy for each sample. The statistical evaluation show that freezing and storage in alcohol do not affect on dissipation and elastic energy of cortical bone. Storage in formalin affect on the dissipation energy, do not affect on elastic energy of cortical bone.
\end{abstract}

Keywords: cortical bone, dissipation energy, elastic energy, compression test

\section{Introduction}

A human body, during its daily activities, is subject to different loads. In most cases those loads are variable in time, however, in some cases those are quasi-cyclic loads, i.e. breathing or walking. As the body moves, the human bones absorb the loads resulting from the body's interaction with the environment. A cortical bone - a component of the human bone has a special function - it transfers the loads from the joint surfaces and distribute those loads over the entire bone. It should be characterized by good elastic properties and good energy absorption properties. Thus, it is crucial to determine those properties of the cortical bone.

The bone as an organic material is a very specific test object. After collecting, it must be stored properly since it may deteriorate over time. Selecting a correct storage method is essential in maintaining the properties of the cortical bone, since an incorrect storage method may affect the results mechanical tests (Linde and Sorensen, 1993 and Topolinski et al., 2011). Thus, the purpose of the study was to determine the effects of those method on changes in the dissipation and elastic energy cortical bone.

\section{Methods}

The study included 30 porcine cortical bone samples. After slaughter, the bones where stored in a cold store at $4{ }^{\circ} \mathrm{C}$. The samples were collected from the femoral shaft from approximately $40 \mathrm{~mm}$ from epiphysis proximalis. The samples were cylindrical in shape with $5 \mathrm{~mm}$ diameter and height. The place collect of samples showed in figure 1 .

Assoc. Prof. Adam Mazurkiewicz, PhD: Department of Mechanical Engineering, University of Sciences and Technology, Kaliskiego 7 Street; 85-789 Bydgoszcz; PL, e-mail: adam.mazurkiewicz@utp.edu.pl

** Assistant Angela Andrzejewska, MSc: Department of Mechanical Engineering, University of Sciences and Technology, Kaliskiego 7 Street; 85-789 Bydgoszcz; PL, e-mail: angela.andrzejewska@utp.edu.pl

*** MSc. Tomasz Małek, PhD candidate: Student Scientific Group BioMed, University of Sciences and Technology, Kaliskiego 7 Street; 85-796, Bydgoszcz; PL, e-mail: tomasz.m.malek@gmail.com 


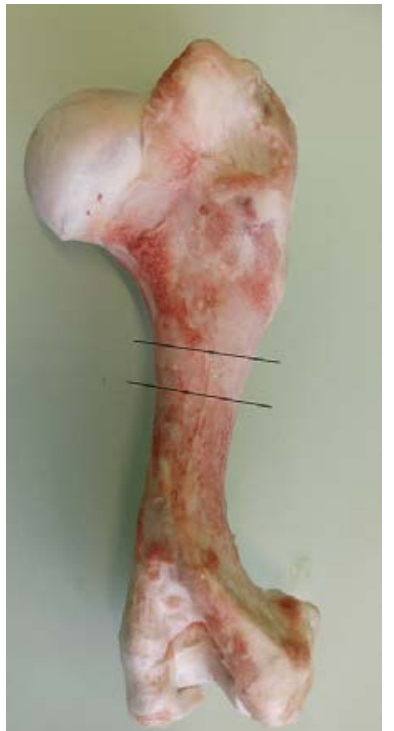

Fig. 1: The place collect of samples.

The samples were divided into 3 groups, 10 samples each. The samples in each group, immediately after collection, were subjected to a compression test. After the test the groups where stored: in a $10 \%$ formalin solution at room temperature, frozen at $-20{ }^{\circ} \mathrm{C}$ and in a $96 \%$ alcohol solution at room temperature. The samples were stored for 30 days. After 30 days the samples from the other groups were subjected to the same test.

In compression test initial $3 \mathrm{~N}$ force was applied to the sample. The strain of the sample at the force was taken as a "zero" point. A total of 20 loading cycles were applied until a $0.65 \%$ strain, which corresponding to a $0.065 \mathrm{~mm}$ displacement. Test was conducted using Instron E3000 testing system (Instron, High Wycombe, England). A elastic and dissipation energy was calculated for each sample based on the shape and size of the loop's surface area recorded during test.

The tested groups included 10 samples each. Due to the difficulties in determining the normality of distribution of the results for a small number of samples, the energy values ratio for each group were evaluated using the Mann-Whitney test at $\mathrm{p}=0.05$. All statistical calculations were performed in "R" software.

\section{Results}

Table 1 shows the test results elastic and dissipation energy calculations.

The results of the Mann-Whitney test were used to determine the differences changes of energies in tested groups. The result test show that the differences in the median dissipation and elastic energy for the samples stored in alcohol and frozen are statistically insignificant (figures 2 and 3). For the samples stored in formalin changes in median value was statistically significant for dissipation energy and statistically insignificant for elastic energy (figure 4).

Tab. 1: Values of energies obtained from compression test.

\begin{tabular}{|c|c|c|c|c|c|c|c|}
\hline & & \multicolumn{2}{|c|}{ Frozen } & \multicolumn{2}{|c|}{ 96\% alcohol } & \multicolumn{2}{|c|}{ Formalin } \\
\hline & & Initial & $\begin{array}{c}\text { After } 30 \\
\text { days }\end{array}$ & Initial & $\begin{array}{c}\text { After } 30 \\
\text { days }\end{array}$ & Initial & $\begin{array}{c}\text { After } 30 \\
\text { days }\end{array}$ \\
\hline $\begin{array}{l}\text { Elastic energy } \mathrm{U}_{\mathrm{s}} \text {, } \\
\mathrm{mJ} / \mathrm{mm}^{3}\end{array}$ & median & 346 & 335 (IS) & 340 & 352 (IS) & 363 & 354 (IS) \\
\hline $\begin{array}{l}\text { Dissipation energy } \\
\mathrm{U}_{\mathrm{d}}, \mathrm{mJ} / \mathrm{mm}^{3}\end{array}$ & median & 158 & 167 (IS) & 163 & 172 (IS) & 154 & $132(\mathrm{~S})$ \\
\hline
\end{tabular}

Change value of median from Mann - Whitney test result: (S) significant, (IS) insignificant 

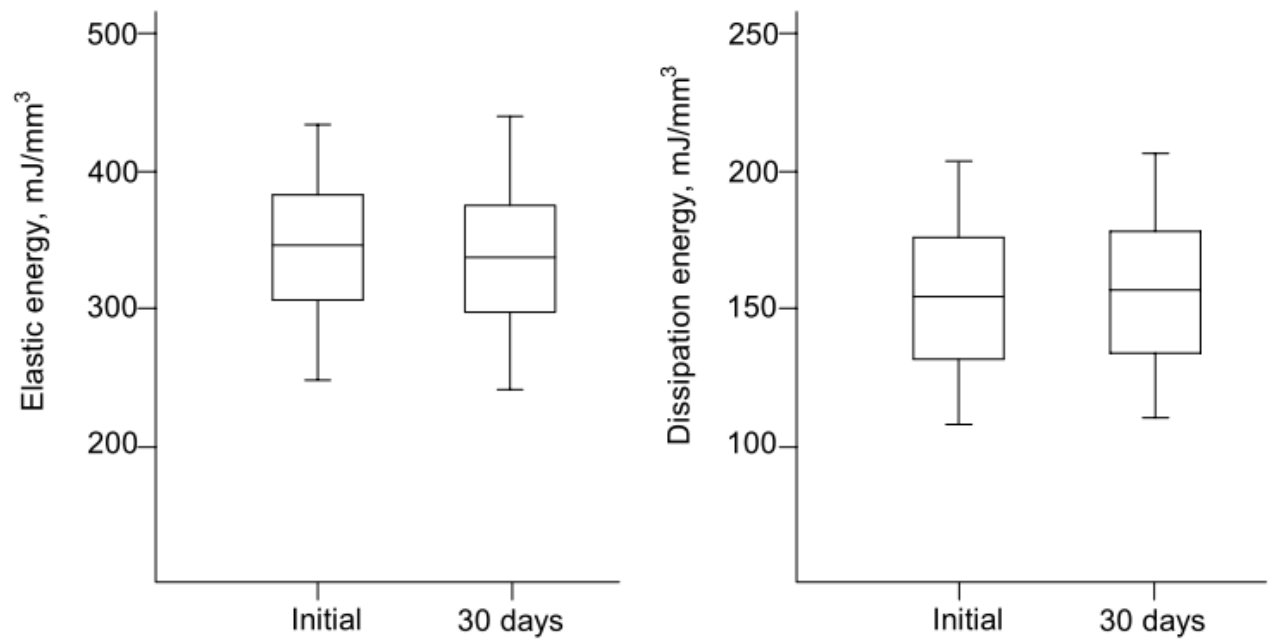

Fig. 2: Changes in elastic and dissipation energy frozen samples.
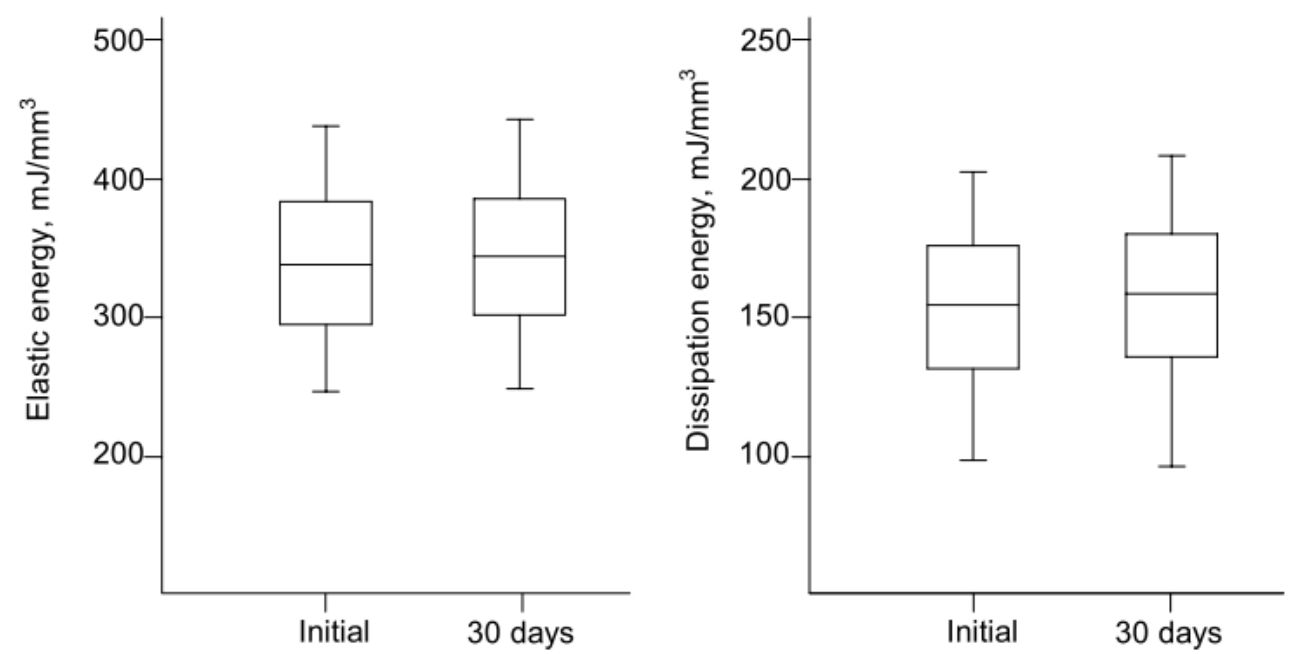

Fig. 3: Changes in elastic and dissipation energy samples stored in 96\% in alcohol.
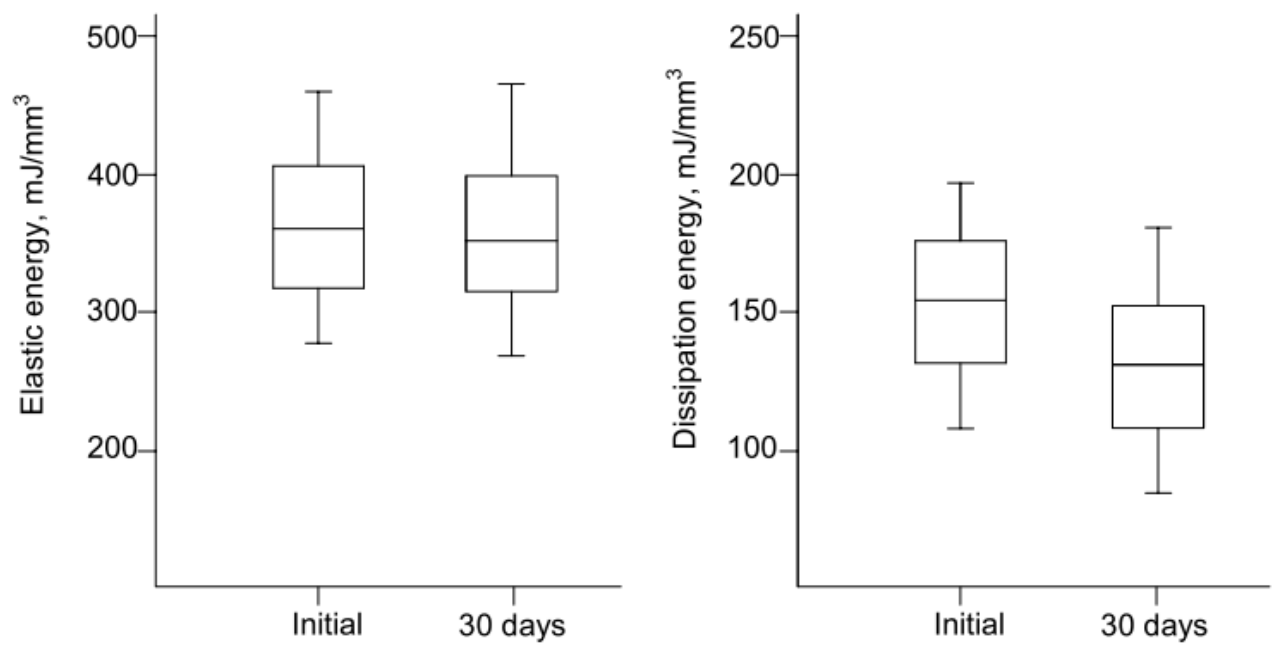

Fig. 4: Changes in elastic and dissipation energy samples stored in formalin. 


\section{Conclusions}

The results Mann - Whitney test evaluated storage methods affect on changes in the dissipation and elastic energy of the cortical bone. The value dissipation energy for samples stored in formalin is lower after 30 days, for a group of samples stored in alcohol and frozen is no change. Elastic energy in all groups is no changed after 30 days. Freezing and storage in alcohol not change dissipation and elastic energy and can be use to storage cortical bone.

A correct sample storage method is a prerequisite to obtaining the correct mechanical test results. The result available in the literature are often contradictory. Some researchers have observed an increase in strength properties for samples stored in a formalin, whereas others have reported a decrease of the same properties (Edmonston et al., 1994; Popperl et al., 1999; Topolinski et al., 2012).

In general analyzing results described in literature is visible absence standardized testing procedures for bone tissue and storage techniques. Lack of standardization in the testing method, its parameters makes it difficult to compare the results obtained by different authors. The same effect shows lack of standards in the methods of sample storage. Different authors examine the impact of storage methods at different time periods and stored in different ways. For example, storage in a $4 \%$ formalin solution gives different results than in a $10 \%$ solution. The same applies to temperature and storage conditions during freezing. Method of protect samples from dehydration during freezing can changes the test results significantly.

Hence the results obtained by other researcher show high variability and indicate that the evaluation may prove difficult (Kikugawa et al., 2004 and Nazarian et al., 2009 and Burkhart et al., 2010 and Unger et al., 2010).

\section{References}

Burkhart, K.J., Nowak, T.E., Blum, J., Kuhn, S., Welker, M., Sternstein W. (2010) Influence of formalin fixation on the biomechanical properties of human diaphyseal bone. Biomed. Tech. (Berl.), 55, 6, pp.361-365.

Edmondston, S. J., Singer, K. P., Day, R. E., Breidahl, P. D. and Price, R. I. (1994) Formalin fixation effects on vertebral bone density and failure mechanics: an in-vitro study of human and sheep vertebrae. Clinical Biomechanics, 9 ,3, pp. 175-179.

Kikugawa, H., Asaka, T. (2004) Effect of long-term formalin preservation on bending properties and facture toughness of bovine compact bone. Materials Transactions, 45, 10, pp. 3060-3064.

Linde, F., Sorensen, H.C. (1993) The effect of different storage methods on the mechanical properties of trabecular bone. J. Biomech., 26, 10, pp. 1249-1252.

Nazarian, A., Hermannsson, B.J., Muller, J., Zurakowski, D., Snyder, B.D. (2009) Effects of tissue preservation on murine bone mechanical properties. J. Biomech., 42, 1, pp.82-86.

Pöpperl, G., Lochmüller, E., Becker, H., Mall, G., Steinlechner, M. and Eckstein, F., (1999) Determination of calcaneal ultrasound properties ex situ: reproducibility, effects of storage, formalin fixation, maceration, and changes in anatomic measurement site. Calcif Tissue Int., 65, 3, pp. 192-7.

Topolinski, T., Cichanski, A., Mazurkiewicz, A. and Nowicki K. (2011) Fatigue Energy Dissipation in Trabecular Bone Samples with Step-wise-Increasing Amplitude Loading. Materials Testing, 53, 6, pp. 344-350.

Topolinski, T., Cichanski, A., Mazurkiewicz, A. et al. (2012) Applying a stepwise load for calculation of the S-N curve for trabecular bone based on the linear hypothesis for fatigue damage accumulation. Mater. Sci. Forum 726, pp. 39-42, doi:10.4028/www.scientific.net/MSF.726.39.

Unger, S., Blauth, M., Schmoelz, W. (2010) Effects of three different preservation methods on the mechanical properties of human and bovine cortical bone. Bone, 47, 6, pp. 1048-1053. 